\title{
The evaluation of the classical Kirby-Bauer antibiogram method for the determination of antibiotic resistant microorganisms in tap water
}

\author{
Agata Siedlecka ${ }^{1, *}$, and Katarzyna Piekarska ${ }^{1}$ \\ ${ }^{1}$ Wroclaw University of Science and Technology, Faculty of Environmental Engineering, Wroclaw, \\ Poland
}

\begin{abstract}
Water supply systems are the main source of potable water for many inhabitants. The European Union and Polish laws demand high quality of tap water, but the aspect of antibiotic resistant bacteria (ARB) is not mentioned. The special emphasis is placed on the presence of pathogenic microorganisms in water, determining by the presence of chosen indicators. Although these regulations provide quite good quality of drinking water, the neglect of resistance vectors could lead to a serious threat to human health. In this study the randomly chosen sample of water from the Wroclaw water supply system was tested in order to evaluate the usefulness of Kirby-Bauer antibiogram method for the assessment of the presence of ARB. The susceptibility testing with 6 chosen antibiotics was performed on bacterial strains isolated from the sample. The diameters of growth inhibition zones were measured and the preliminary identification of strains was carried out, including Gram staining and bacterial cellular morphologies assessments. Although full recognition of the drug resistance phenomenon demands the identification of bacterial species for the comparison with susceptibility testing guidelines, this preliminary research could answer the question, whether the Kirby-Bauer method is sufficient for investigations of ARB dwelling in Wroclaw tap water or the other solution should be applied.
\end{abstract}

\section{Introduction}

The safety of potable water is one of the most important factors affecting human health. It is obvious, that the intake of poorly treated drinking water could lead to the outbreak of an epidemic caused by pathogenic and opportunistic microorganisms dwelling in contaminated water, as it was in Peru, 1991, as the result of negligence the disinfection of drinking water in water supply systems [1]. According to the Polish law, the quality of tap water in terms of microbiological contamination is assessed by regarding the presence of the chosen indicators: coliform bacteria, thermotolerant coliform bacteria, Escherichia coli species, Streptococcus faecalis species and Clostridium spp. (in extended research), as the presence of these bacteria in water samples could be easily identified and they fulfil

*Corresponding author: agata.siedlecka@pwr.edu.pl 
the conditions of faecal contamination indicators, i.e. they are the typical human intestinal pathogens, do not form the spores (allowing to detect the recent contamination), their lifespan is longer than the lifespan of pathogens, etc. [2]. Though these regulations provide the suitable quality of treated tap water, the antibiotic resistance factor is completely neglected. There is no guideline to identify antibiotic resistant bacteria (ARB) or antibiotic resistance genes (ARGs) in drinking water and there is no research applied regarding this matter. However, the literature review indicates, that the aspect of antibiotic resistance of bacteria dwelling in tap water is present all over the world, as, for example, tetracycline and chloramphenicol resistant $E$. coli revealed in a public rural water supply system in France [3], and could be perceived as the emerging threat, since the presence of ARB or ARGs leads to the further prevalence of antibiotic resistance in the environment and, if consumed with potable water, in human organisms [4, 5]. From this point of view, resistant species dwelling in tap water (as well as free ARGs), even if harmless, could be considered as potential resistance vectors, since they could transfer the resistance features to pathogenic strains, hereby contributing to the appearance of pathogenic, resistant strains.

The presence of ARB in tap water may be due to water treatment processes, especially biological activated carbon, ozonation and chlorine disinfection units [6], as in these processes bacteria could acquire new features because of their genomic flexibility [7]. Users of drinking water contaminated with ARB could be carriers of resistant microorganisms, as proven in Canada with resistant E. coli strains [8]. From antibiotic resistance point of view, the safety of drinking water is not provided even if resources of water are groundwater, especially in karst terrain area [3].

The aim of this study is to evaluate the classical, Kirby-Bauer antibiogram method as a tool for the determination of ARB dwelling in tap water. At the same time, the authors made the attempt to preliminary assess whether there is an antibiotic resistance phenomenon among the bacteria isolated from the Wroclaw tap water sample, although with the presented data only rough assumption may be implemented regarding this matter.

\section{Materials and methods}

\subsection{Sample collection and isolation of microorganisms}

In order to isolate bacterial strains dwelling in tap water, $1 \mathrm{~L}$ of the water sample was collected to sterile, $1 \mathrm{~L}$ blue-cap bottle. The sampling point was located in the laboratory at the Faculty of Environmental Engineering at Wroclaw University of Science and Technology. The sampling was carried out according to the procedure described in Kańska et. al. [9]: the tap was chemically disinfected and the sample of water was collected after 10 minutes of not disturbed water flow to eliminate the risk of the intake of bacteria dwelling near the entrance of the tap. Immediately afterwards, $1 \mathrm{~L}$ of drinking water was filtrated through the sterile mixed cellulose ester membrane filters, pore size $0.2 \mu \mathrm{m}$, diameter $50 \mathrm{~mm}\left(\right.$ Whatman $^{\mathrm{TM}}$ ) in the sterile filter unit (Nalgene $\left.{ }^{\circledR}\right)$. The filters were placed on R2A agar plates (BTL) and incubated at $22^{\circ} \mathrm{C}$ and $37^{\circ} \mathrm{C}$ for 5 days. Several randomly chosen colonies of each filter were subjected to the further testing and isolated on R2A agar plates [10]. After 4 days of incubation at the optimal temperatures (i.e. $22^{\circ} \mathrm{C}$ and $37^{\circ} \mathrm{C}$ ) pure bacterial strains were transferred to R2A agar slants and further incubated. All the isolated strains were stained according to the procedure described as Gram staining [10] with the purpose of the preliminary differentiation. 


\subsection{Antibiotic susceptibility testing}

The isolated strains were subjected to antibiotic susceptibility testing. In this approach, the classical Kirby-Bauer antibiogram method, as well as modified antibiogram methods were applied, as strains dwelling in tap water are known to have different features (i.a. nutrient and temperature requirements) than pathogenic strains, for which the standard antibiogram was elaborated [11].

6 widely known and frequently applied antibiotics of different antibiotic classes [12] were chosen, as presented in the table 1 . Beyond tetracycline, all these antibiotics were applied in ARB research in surface and drinking water distribution systems in South Africa [13].

Table 1. Antibiotics selected for the disk diffusion method.

\begin{tabular}{|c|c|c|c|}
\hline Antibiotic & Class of antibiotics & Assay [mcg/disc] & Symbol \\
\hline tetracycline & tetracyclines & 32.9 & TE 30 \\
\hline kanamycin & aminoglycosides & 31.6 & K 30 \\
\hline erythromycin & macrolides & 16.1 & E 15 \\
\hline amoxicillin & aminopenicillins & 11.7 & AX 10 \\
\hline chloramphenicol & chloramphenicols & 32.8 & C 30 \\
\hline trimethoprim & synthetic chemotherapeutic & 5.9 & TMP 5 \\
\hline
\end{tabular}

According to Kirby-Bauer antibiogram procedures [11], density of bacterial strains solutions was adjusted to 0.5 McFarland standard (bioMerieux) by suspending the inoculum in sterile saline $(0,9 \% \mathrm{NaCl})$. Subsequently, Mueller-Hinton agar (BioMaxima) plates were swabbed and within 15 minutes the sterile cotton antimicrobial susceptibility test discs (BioMaxima) were placed onto plates. Each strain was subjected the incubation at recommended $35^{\circ} \mathrm{C}$ and its optimal temperature, i.e. $22^{\circ} \mathrm{C}$ or $37^{\circ} \mathrm{C}$, for the comparison of their growth under the different temperature conditions on MuellerHinton agar. The incubation period was 5 days.

\section{Results}

\subsection{Characterization of microorganisms}

The membrane filter incubated at $37^{\circ} \mathrm{C}$ overgrew with white, yellow and orange colonies of different sizes (varying from $<0.5 \mathrm{~mm}$ to $5 \mathrm{~mm}$ ), while the membrane filter incubated at $22^{\circ} \mathrm{C}$ overgrew with white and yellow colonies of different sizes (varying from $<0.5 \mathrm{~mm}$ to $3 \mathrm{~mm}$ ). Except the differences in pigmentation, size and height, the colonies shape (punctiform / round), surface (smooth), texture (butyrous) and edge (entire) were similar. The results of the cultivation of microorganisms concentrated on membrane filters are shown in the Fig. 1.

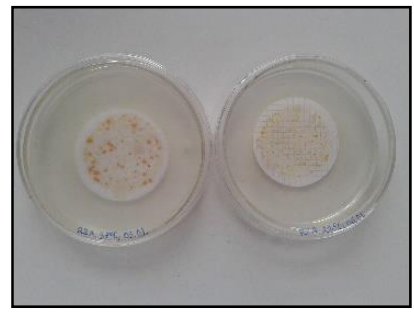

Fig. 1. Membrane filters incubated at $37^{\circ} \mathrm{C}$ (left) and $22^{\circ} \mathrm{C}$ (right) after 5 days of incubation. 
As the results of the isolation procedure [10], 26 pure strains were obtained, including 13 mesophilic $\left(37^{\circ} \mathrm{C}\right.$, no $\left.1-13\right)$ and 13 psychrophilic $\left(22^{\circ} \mathrm{C}\right.$, no $\left.14-26\right)$ strains. Most of the strains turned out to be gram-negative coccobacilli, but in some cases also grampositive cocci were revealed, indicating the pleomorphism phenomena. Moreover, grampositive bacilli were observed. Nevertheless, further investigations must be implemented in order to identify the obtained strains.

\subsection{Antibiotic susceptibility testing}

The diameters of zones of inhibited bacterial growth were measured for each strain incubated on Mueller-Hinton agar at $35{ }^{\circ} \mathrm{C}$, as well as for the strains incubated at their optimal temperatures (i.e. $37^{\circ} \mathrm{C}$ for the strains numbered as $1 \div 13$ and $22^{\circ} \mathrm{C}$ for the strains numbered as 14-26). Not every strain was exposed to every drug and few of the strains were incubated without any antibiotic disc, in order to observe its non-disturbed growth on Mueller-Hinton agar. The table 2 presents the values of diameters [mm] obtained after incubation at $35^{\circ} \mathrm{C}\left(\mathrm{T}_{35}\right)$ and $37^{\circ} \mathrm{C}$ or $22^{\circ} \mathrm{C}\left(\mathrm{T}_{\text {opt }}\right)$ around the applied antibiotic disks, marked as their symbols (look at the Table 1). In cases where there was no inhibition, ' 0 ' was measured, neglecting the diameter of the cotton disk.

Table 2. The diameters of inhibited growth. "- ' means that there was not any growth on the plate, so the diameters could not be read. ' 0 ' means that there was no inhibition of growth (despite the presence of the disk). 'CL' means 'control' - the strain cultivated without any antibiotic disk. 'N/D' means 'no data' - the given antibiotic was not applied.

\begin{tabular}{|c|c|c|c|c|c|c|c|c|c|c|c|c|}
\hline \multirow{2}{*}{ Strain no } & \multicolumn{2}{|c|}{$\mathrm{TE} 30$} & \multicolumn{2}{|c|}{$\mathrm{K} 30$} & \multicolumn{2}{c|}{$\mathrm{E} 15$} & \multicolumn{2}{c|}{$\mathrm{AX} 10$} & \multicolumn{2}{c|}{$\mathrm{C} 30$} & \multicolumn{2}{c|}{ TMP 5 } \\
\cline { 2 - 16 } & $\mathrm{T}_{35}$ & $\mathrm{~T}_{\mathrm{opt}}$ & $\mathrm{T}_{35}$ & $\mathrm{~T}_{\mathrm{opt}}$ & $\mathrm{T}_{35}$ & $\mathrm{~T}_{\mathrm{opt}}$ & $\mathrm{T}_{35}$ & $\mathrm{~T}_{\mathrm{opt}}$ & $\mathrm{T}_{35}$ & $\mathrm{~T}_{\mathrm{opt}}$ & $\mathrm{T}_{35}$ & $\mathrm{~T}_{\mathrm{opt}}$ \\
\hline 1 & - & - & - & - & - & - & - & - & - & - & - & - \\
\hline 2 & - & - & - & - & - & - & - & - & - & - & - & - \\
\hline 3 & - & - & - & - & - & - & - & - & - & - & - & - \\
\hline 4 & - & - & - & - & - & - & - & - & - & - & - & - \\
\hline 5 & - & - & - & - & - & - & - & - & - & - & - & - \\
\hline 6 & - & - & - & - & - & - & - & - & - & - & - & - \\
\hline 7 & 40 & 36 & $\mathrm{~N} / \mathrm{D}$ & 28 & 39 & 36 & 20 & 20 & 26 & 14 & 38 & 34 \\
\hline 8 & - & - & - & - & - & - & - & - & - & - & - & - \\
\hline 9 & - & - & - & - & - & - & - & - & - & - & - & - \\
\hline 10 & - & - & - & - & - & - & - & - & - & - & - & - \\
\hline 11 & $\mathrm{CL}$ & $\mathrm{CL}$ & $\mathrm{CL}$ & $\mathrm{CL}$ & $\mathrm{CL}$ & $\mathrm{CL}$ & $\mathrm{CL}$ & $\mathrm{CL}$ & $\mathrm{CL}$ & $\mathrm{CL}$ & $\mathrm{CL}$ & $\mathrm{CL}$ \\
\hline 12 & 55 & 60 & $\mathrm{~N} / \mathrm{D}$ & $\mathrm{N} / \mathrm{D}$ & $\mathrm{N} / \mathrm{D}$ & $\mathrm{N} / \mathrm{D}$ & 26 & $\mathrm{~N} / \mathrm{D}$ & 40 & $\mathrm{~N} / \mathrm{D}$ & 0 & 0 \\
\hline 13 & $\mathrm{CL}$ & $\mathrm{CL}$ & $\mathrm{CL}$ & $\mathrm{CL}$ & $\mathrm{CL}$ & $\mathrm{CL}$ & $\mathrm{CL}$ & $\mathrm{CL}$ & $\mathrm{CL}$ & $\mathrm{CL}$ & $\mathrm{CL}$ & $\mathrm{CL}$ \\
\hline 14 & $\mathrm{CL}$ & $\mathrm{CL}$ & $\mathrm{CL}$ & $\mathrm{CL}$ & $\mathrm{CL}$ & $\mathrm{CL}$ & $\mathrm{CL}$ & $\mathrm{CL}$ & $\mathrm{CL}$ & $\mathrm{CL}$ & $\mathrm{CL}$ & $\mathrm{CL}$ \\
\hline 15 & - & 60 & - & $\mathrm{N} / \mathrm{D}$ & - & 23 & - & 0 & - & 36 & 24 & 0 \\
\hline 16 & - & - & - & - & - & - & - & - & - & - & - & - \\
\hline 17 & - & 56 & - & 26 & - & 19 & - & 0 & - & 36 & - & 16 \\
\hline 18 & 45 & 48 & $\mathrm{~N} / \mathrm{D}$ & 36 & $\mathrm{~N} / \mathrm{D}$ & 28 & 20 & 22 & 44 & 44 & 0 & 14 \\
\hline 19 & 46 & 40 & 48 & 34 & 36 & 24 & 20 & 21 & 50 & 44 & 0 & 12 \\
\hline 20 & 58 & 60 & $\mathrm{~N} / \mathrm{D}$ & $\mathrm{N} / \mathrm{D}$ & 22 & 18 & $\mathrm{~N} / \mathrm{D}$ & $\mathrm{N} / \mathrm{D}$ & $\mathrm{N} / \mathrm{D}$ & $\mathrm{N} / \mathrm{D}$ & $\mathrm{N} / \mathrm{D}$ & $\mathrm{N} / \mathrm{D}$ \\
\hline 21 & 44 & 34 & 42 & 34 & 30 & 30 & 15 & 16 & 45 & 40 & 0 & 0 \\
\hline 22 & - & 44 & - & 50 & - & 20 & - & 0 & - & 36 & - & 27 \\
\hline 23 & - & 58 & - & 44 & - & $\mathrm{N} / \mathrm{D}$ & - & 12 & - & 34 & - & 34 \\
\hline 24 & - & - & - & 50 & - & $\mathrm{N} / \mathrm{D}$ & - & 30 & - & - & - & - \\
\hline 25 & 50 & 44 & $\mathrm{~N} / \mathrm{D}$ & 42 & 38 & $\mathrm{~N} / \mathrm{D}$ & 16 & 24 & 50 & 44 & 0 & 16 \\
\hline 26 & - & 50 & - & $\mathrm{N} / \mathrm{D}$ & - & 41 & - & 20 & - & - & - & - \\
\hline
\end{tabular}




\section{Discussion and conclusions}

According to antibiotic susceptibility testing guidelines, drug resistance could be determined only when the species of tested microorganisms are established [14]. Seemingly, without these data, only the rough assumption might be implemented. However, these elaborated databases are the perfect tool mainly for antimicrobial susceptibility assessments of clinically relevant strains, as pathogenic strains, and it is likely, that species isolated from tap water samples are not included in these guidelines, as apparently harmless ones. This shortage must be overcome by assumptions based on the given diameters of zones of inhibited bacterial growth for known, pathogenic species, for preliminary determination of the potential drug resistance. Thereby, the cut-offs of diameters were accepted as following:

- resistant, when the diameter is $<10 \mathrm{~mm}$

- intermediate, when the diameter is $10 \div 20 \mathrm{~mm}$

- $\quad$ susceptible, when the diameter is $>20 \mathrm{~mm}$.

Although these assumptions might be regarded as too lenient and contribute to the omitting of truly resistant species, the results show that even under these circumstances many strains could be considered resistant. Indeed, the cut-off values differ for various antibiotics, as well as for various species.

According to the assumption presented above, only amoxycillin and trimethoprim could be regarded as potential non-effective drugs and resistance to erythromycin, amoxycillin, chloramphenicol (just in one case) and trimethoprim could be regarded as intermediate. Tetracycline and kanamycin appear to be efficient against the obtained strains. For the mesophilic strains (no $1-13$ ), the diameters measured in $35^{\circ} \mathrm{C}$ and $37^{\circ} \mathrm{C}$ did not differ significantly, as the difference of temperature conditions was irrelevant. However, for the psychrophilic strains (no 14-26), these differences tend to be essential in many cases. Some strains appear to be susceptible, when incubated at $35^{\circ} \mathrm{C}$ but resistant, when incubated at $22^{\circ} \mathrm{C}$. This lead to the conclusion, that classical Kirby-Bauer antibiogram method is not the appropriate tool for psychrophilic microorganisms.

Most of the selected antibiotics used in this study are known to have a broad-spectrum against gram-positive and gram-negative strains (except erythromycin, which is effective mainly against gram-positive strains, although in this study gram-negative coccobacilli revealed to be susceptible to erythromycin). To confirm the obtained results, further investigations must be applied, including the classification of the strains to species.

This preliminary research is the evidence, that the classical Kirby-Bauer antibiogram method is the insufficient tool for the investigations of ARB dwelling in tap water. Water supply systems are the specific environment for microorganisms, because of the following features [15]:

- concentration of nutrients (i.a. organic carbon), which is strongly limited

- temperature conditions, which are not suitable for many bacterial species

- occasionally inconvenient hydraulic conditions (i.a. water stagnation)

- lack of light, lack of many competitive species

These features make that water supply systems could be regarded as the niche, where only the minor part of whole plethora of microorganisms are able to survive, but still, the biodiversity of biofilm and planktonic forms of microorganisms occurring in pipes is wide, as it is shown in the numerous studies [15-17]. It is worth to mention that the guidelines for susceptibility testing are still subjected to changes and improvements, as new data are taken into account. This leads to many critical evaluations of CLSI (NCCSL) and EUCAST handbooks [18-21], but to date, as indicated in this study, there is a lack of knowledge and outlines for many species. 
The main disadvantages, that make the Kirby-Bauer antibiorgam method inappropriate for bacteria of water-pipelines origin are the following:

- tap water microorganisms generally grow slowly, so the cultivation period need to be extended. It is almost impossible to use the fresh, 18-hour culture for testing, as recommended [11]

- adjusting the inoculum to $0.5 \mathrm{McF}$ arland standard should provide the even growth on Mueller-Hinton agar plates - however the results showed, that many isolated strains created separated colonies

- the recommended height of Mueller-Hinton agar on a $100-\mathrm{mm}$ plate (petri dish) is $4 \mathrm{~mm}$ [11], but during the incubation at $35^{\circ} \mathrm{C}$ more than 3 -days agar of that height may dry up

- ingredients of Mueller-Hinton agar make it rich in nutrients medium, and because of this, bacteria cultivated previously on poorer R2A agar could be unable to adapt to new conditions

- tap water microorganisms transferred from their natural environment to the laboratory and cultivated on agar medium could have changed their biochemical and physiological features, lost their characteristics and even DNA sequences (plasmid loss), what could make the attempts to identify the strains unsuccessful, hereby precluding the eventual susceptibility testing confirmation. From this point of view, the authors suggest, that in respect of the investigations of antibiotic resistance phenomena in tap water, research focused on DNA (i.e. ARGs), rather than ARB cultivation, should be applied

- it is obvious, that plenty of microorganisms of each environment cannot be cultivated on agar medium in laboratory conditions. There is the assumption, that only several percentage of bacterial biodiversity are able to be obtained and the main part remains elusive and could be tested only by metagenomics tools [22]. These considerations are important also for the anaerobic forms of bacteria and strains requiring extremely incubation conditions. Instead of the Kirby-Bauer antibiogram method, ATB panels (Antibiotic Susceptibility Testing Strips, bioMérieux) could be applied [16], nevertheless this tool also requires cultivable, oxidant microbial colony to be tested. Other studies revealed that in water supply systems the alterations in the composition of the bacterial community were higher among cultivable communities than 16S rRNA sequences [17], indicating that some part of biomass could be lost during the classical isolation procedure. That could lead to the omission of many ARB.

In view of the fact that the isolated strains were selected randomly from all colonies obtained from the tap water sample, it is possible, that majority of them belongs to the same genus or even species, what in turn could explain the similar antibiotic resistance profiles of several investigated strains. Therefore, the classification of these strains is needed and should be implemented in further research. In fact, it is worth to mention that the obtained strains could be naturally resistant, i.e. biochemically invulnerable to selected antibiotics applied in this study.

There are many studies which contribute to broadening the knowledge of ARB in tap water, but to date, the majority of them are focused on pathogenic or opportunistic isolates. Therefore, it is crucial to underline, that resistant tap water strains, even if harmless, could act simply as the resistance vectors (e.g ARGs) and from this point of view could be regarded as a potential threat and should be monitored.

The conference participation was financed from the statutory funds of Faculty of Environmental Engineering, Wroclaw University of Science and Technology from the project 0401/0066/16. 


\section{References}

1. https://www.cdc.gov/Mmwr/preview/mmwrhtml/00001912.htm [24/01/2017]

2. A. Grabińska-Łoniewska, E. Siński, Mikroorganizmy chorobotwórcze i potencjalnie chorobotwórcze $w$ ekosystemach wodnych $i$ sieciach wodociagowych (SeidelPrzywecki, Warszawa, 2010)

3. E. Laroche, F. Petit, M. Fournier, B. Pawlak, J. Hydrol. 392, 12-21 (2010)

4. V. Figueira, E.A. Serra, I. Vaz-Moreira, T.R.S. Brandâo, C.M. Manaia, J. Water Health 10, 1 (2012)

5. S.G. Mulamattathil, C. Bezuidenhout, M. Mbewe, C.N. Ateba, J. Pathogens 2014, ID 371208 (2014)

6. X. Bai, X. Ma, F. Xu, J. Li, H. Zhang, X. Xiao, Sci. Total Environ. 533, 24-31 (2015)

7. C. Narciso-da-Rocha, I. Vaz-Moreira, C.M. Manaia, Sci. Total Environ. 466-467, 127-135 (2014)

8. B.L. Coleman, M.I. Salvadori, A.J. McGeer, K.A. Sibley, N.F. Neumann, S.J. Bondy, I.A. Gutmanis, S.A. McEwen, M. Lavoie, D. Strong, I. Johnson, F.B. Jamieson, M. Louie, ARO Water Study Group, Epidemiol. Infect. 140, 633-642 (2012)

9. Z. Kańska, A. Grabińska-Łoniewska, M. Łebkowska, E. Rzechowska, Ćwiczenia laboratoryjne z biologii sanitarnej, czesść I (Oficyna Wydawnicza Politechniki Warszawskiej, Warszawa, 2006)

10. E. Kocwowa, Ćwiczenia z mikrobiologii ogólnej (Państwowe Wydawnictwo Naukowe, Warszawa, 1984)

11. R. Schwalbe, L. Steele-Moore, A.C. Goodwin (ed.), Antimicrobial Susceptibility Testing Protocols (CRC Press, Boca Raton, 2007)

12. Z. Markiewicz, Z.A. Kwiatkowski, Bakterie antybiotyki lekooporność (Wydawnictwo Naukowe PWN, Warszawa, 2001)

13. S.G. Mulamattathil, C. Bezuidenhout, M. Mbewe, S. Afr. J. Sci. 110, 11/12 (2014)

14. CLSI. Performance Standards for Antimicrobial Susceptibility Testing, (Clinical and Laboratory Standards Institute, Wayne, 2017)

15. T. Traczewska, M. Sitarska, I. Biedroń, Ekologiczne i techniczne aspekty powstawania biofilmu w wodzie (Oficyna Wydawnicza Politechniki Wrocławskiej, Wrocław, 2014)

16. I. Vaz-Moreira, O.C. Nunes, C.M. Manaia, Appl. Environ. Microbiol. 77, 16 (2011)

17. I. Vaz-Moreira, C. Egas, O.C. Nunes, C.M. Manaia, FEMS Microbiol. Ecol. 83, 361-374 (2013)

18. M. Hombach, P. Courvalin, E.C. Böttgera, Antimicrob. Agents Ch. 58, 7 (2014)

19. J.A. Kiehlbauch, G.E. Hannett, M. Salfinger, W. Archinal, C. Monserrat, C. Carlyn, J. Clin. Microbiol. 38, 9 (2000)

20. A. Rodloff, T. Bauer, S. Ewig, P. Kujath, E. Müller, Dtsch. Arztebl. Int. 105, 39 (2008)

21. L.N. Mutanda, A.M. Omari, I.A. Wamola, East Afr. Med. J. 66, 7 (1989)

22. T.A. Brown, Genomy (Wydawnictwo Naukowe PWN, Warszawa, 2012) 